\title{
IMPROVEMENT OF THE MICROFLUIDIC DEVICE FOR THE GENERATION OF MONODISPERSE MICROBUBBLES AS DRUG TRANSPORT SYSTEMS
}

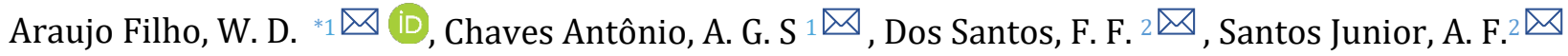 \\ ${ }^{1}$ State University of Bahia (UNEB) - Collegiate of Physics-Department of Exact and Earth Sciences (DCET 1) - \\ Micro Fluidic Laboratory (LAMIC). \\ ${ }^{2}$ State University of Bahia (UNEB) - Department of Life Sciences (DCV), Laboratory of Biopharmacy and Drug \\ Analysis.
}

Received 21 July 2021
Accepted 06 August 2021
Published 31 August 2021

CorrespondingAuthor

Araujo Filho, W. D.,

wfilho@uneb.br

DOI

10.29121/granthaalayah.v9.i8.2021. 4145

Funding: This research received no specific grant from any funding agency in the public, commercial, or not-for-profit sectors.

Copyright: (C) 2021 The Author(s). This is an open access article distributed under the terms of the Creative Commons Attribution License, which permits unrestricted use, distribution, and reproduction in any medium, provided the original author and source are credited.

\section{ABSTRACT}

INTRODUCTION: The localized delivery of drugs has been established since the early eighties of the 20th century as a promising alternative for the localized treatment of tumours, based on the mitigation of side effects produced by traditional methods, notably the administration of chemotherapy by systemic route. Countless scientific works have been dealing with this theme in an attempt to make this therapeutic technique viable and accessible. One of the ways to take the drug to the chosen site is through the use of microbubbles as drug carrier units activated through an ultrasonic field with adequate wavelength and frequency. Therefore, these units must have very peculiar characteristics, such as dimensions, homogeneity, echogenicity and structural characteristics, in addition to the ability to take the therapeutic vector intact to the desired location. In the generation of microbubbles, microfluidic devices of different geometries and different configurations are used, according to the state of the art related to this theme.

DEVELOPMENT: In this work the technique used is the fabrication of micro fluidic devices using 3D printing. With this technique, it is possible to manufacture the devices in a single step, eliminating time-consuming and more complex intermediate procedures. The devices were manufactured using an Object Eden 250 printer, using the transparent resin VeroClear®. With these devices it was possible to produce microbubbles with diameters of the order of $16-73 \mu \mathrm{m}$ with degrees of poly dispersion less than $1 \%$. However, there are difficulties to be overcome, notably with regard to the final composition of the devices. Due to the physical characteristics of the microbubble, notably in relation to its lipid coating layer, the search for drug transport systems is an important strategy.

CONCLUSION: In this work, an account of these difficulties will be made, in addition to the proposition of alternatives to overcome them. Additionally, compatible drugs will be suggested to be attached to microbubbles according to their structural composition.

Keywords: Microbubbles, Ultrasound, Drugs, Tumours Treatment

\section{INTRODUCTION}

The use of microbubbles as auxiliary units in the diagnosis of diseases began in the 1980s of the 20th century Pancholi, K., E. Stride, et al. 2008. Initially, they were used to increase the contrast of ultrasound images in echocardiographic exams Lindner, J. R., S. Kaul. 2001. Microbubbles are microstructures that have 
a gaseous core and are coated with a lipid or polymeric layer that, when loaded with a specific gas, have specific acoustic properties that make them very useful as ultrasound contrast agents for imaging diagnosis (Figure 1).

\section{Microbubble}

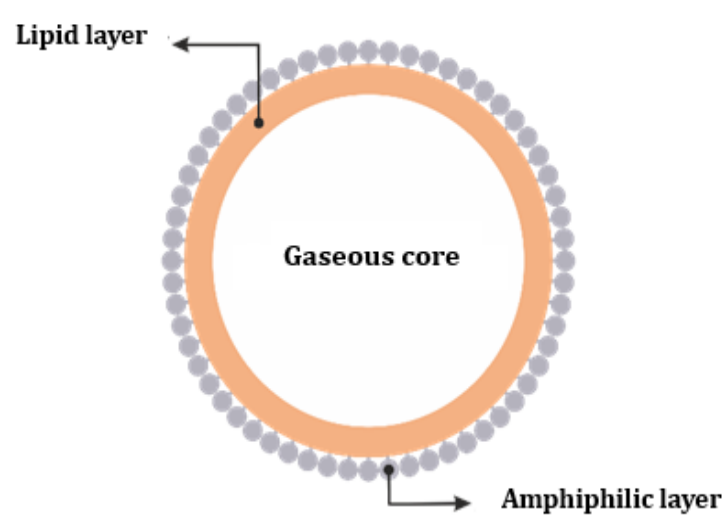

Figure 1 Graphic representation of a microbubble, emphasizing the gaseous core, lipid layer and a second layer consisting of an amphiphilic compound.

This echocardiographic expedient has been used to improve the visibility of the endocardial borders and the analysis of myocardial perfusion. The application of ultrasonic pulses with a high mechanical index (MI) result in the cavitation of the microbubbles and their consequent rupture, releasing the gas, allowing contrast of the myocardial walls Lindner, J. R., S. Kaul. 2001, Stride, E. 2009, Stride, E. 2009. From then on, the possibility of using microbubbles as a therapeutic agent in the localized treatment of diseases was opened. The microbubbles act as drug carrier agents that act in a certain chosen location, and through an ultrasonic pulse, it effects the localized release of the drug. Furthermore, they can act in specific locations or to accelerate thrombus dissolution. Recent developments have demonstrated the feasibility of using microbubbles as carrier agents for localized delivery of drugs suitable for the treatment of tumours EC Unger, T Porter, W Culp, R label, T Matsunaga, R Zutshi 2004, Lajoline, G. et al. 2016. Well-known for its use, ultrasound can also be used to control the drug release time when transported by a microbubble. This type of therapeutic procedure is a promising modality, especially in cases where high concentrations of drugs are administered in a systemic way, causing undesirable side effects Fiorini, D. T. Chiu 2005. The mitigation of these side effects induces a better quality of life of patients, reducing the possibility of subsequent hospitalization, and often preventing deaths.

Seeking the generation of microbubbles, microfluidic devices were designed and manufactured using 3D printing Araujo Filho, W. D. et al, Araujo Filho, W. D.; Araujo, L. M.P., Araujo Filho, W. D.; Araujo, L. M.P., Araujo Filho, W. D.; Araujo, L. M.P.; Menezes, D. O.; Mauricio, C. R. M. 2019 3D.

Figure 2 shows two configurations of devices manufactured according to the above technique. 

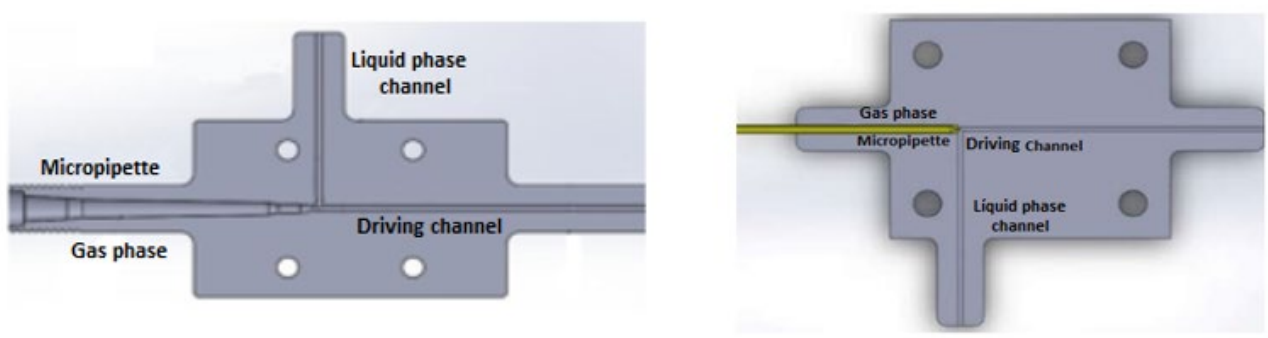

Figure 2 Two configurations of devices manufactured according to the above technique.

In Figure 3 is shown the main dimensions of the devices and the diameter of the channels, you can also observe the micropipette coupled upstream of the driving channel.

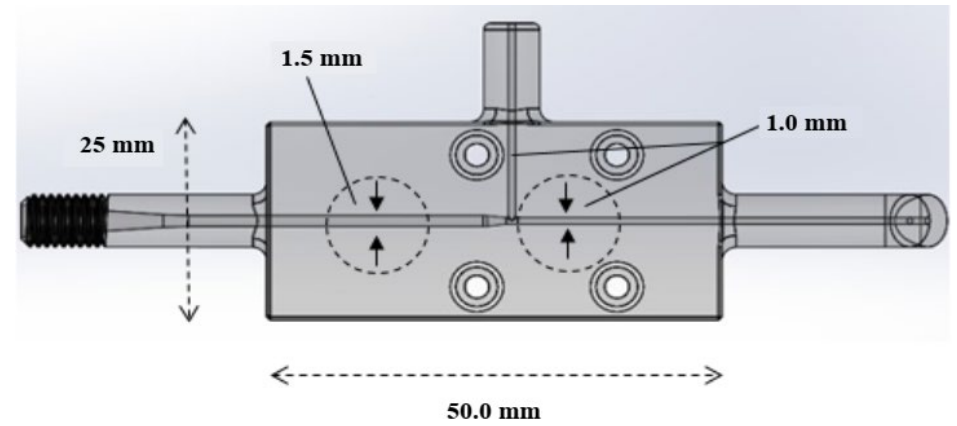

Figure 3 Main dimensions of the devices and the diameter of the channels, you can also observe the micropipette coupled upstream of the driving channel.

Figure 4 presents a three-dimensional representation of the device manufactured using the 3D printing technique.

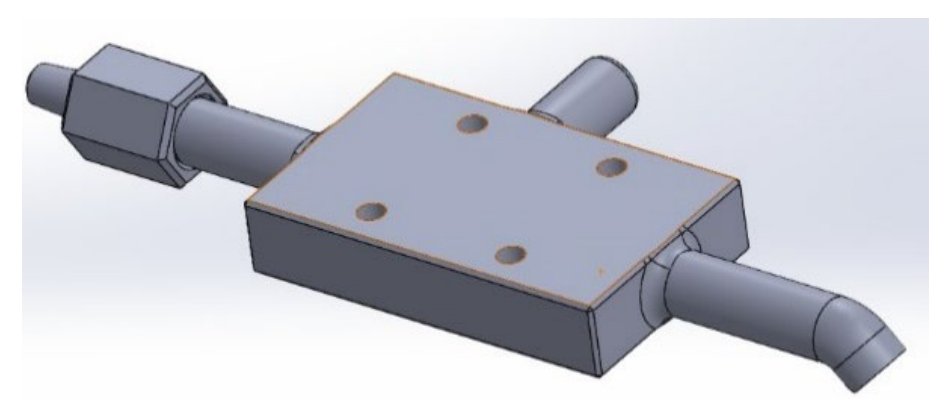

Figure 4 Three-dimensional representation of the device manufactured using the 3D printing technique.

The microfluidic systems manufactured in accordance with the aforementioned technique partially met the expectations, with microbubbles of the order of $16-73$ $\mu \mathrm{m}$ in diameter having been obtained with degrees of poly dispersion smaller than 1\% Araujo Filho, W. D. et al, Araujo Filho, W. D.; Araujo, L. M.P.,Araujo Filho, W. D.; Araujo, L. M.P.Araujo Filho, W. D.; Araujo, L. M.P.; Menezes, D. O.; Mauricio, C. R. M. 2019 3D, which somehow approximates the ideal size, which rotates in around 10$12 \mu \mathrm{m}$ (approximate size of a red cell). 
The dynamic process of production of microbubble is based in micro fluidics, form bubbles by gas/liquid T Fu, Y Ma, D Fun schilling, HZ li 2009, Y Hong, F Wang 2007TM Squires, SR Quake 2005E stride, M Edirisinghe 2008. The bubble size is associated with the physical properties of the liquid flow rates of gas and liquid phase, the size and profile of the channels, besides the speed of strangulation $P$ Garstecki, I Gitlin, W Diluzio, GM Whitesides, E Kumacheva, 2004, Stride, E. 2009, Borden, M. A., M. L. Longo. 2002.

This, in turn, is dependent on the rate of fluid flow and pressure of gas should be increased or decreased. For a given gas pressure, there is a maximum flow of fluid above which the gas flow is blocked, there is no formation of microbubbles as well as the indiscriminate increase in pressure induces an atomization (spray) of the liquid phase. Thus, the formation mechanism of the bubble is significantly influenced by the variation of these parameters, particularly the viscosity of the liquid Borden, M. A., M. L. Longo. 2002.

The ordered control of these variables plays a key role in their size. The choice of the T-junction device occurred due to its simplicity and high efficiency demonstrated by several of papers published in specialized journals Stride, E., M. Edrisinghe. 2009. Figure 5 shows the microbubble generated from the microfluidic device.

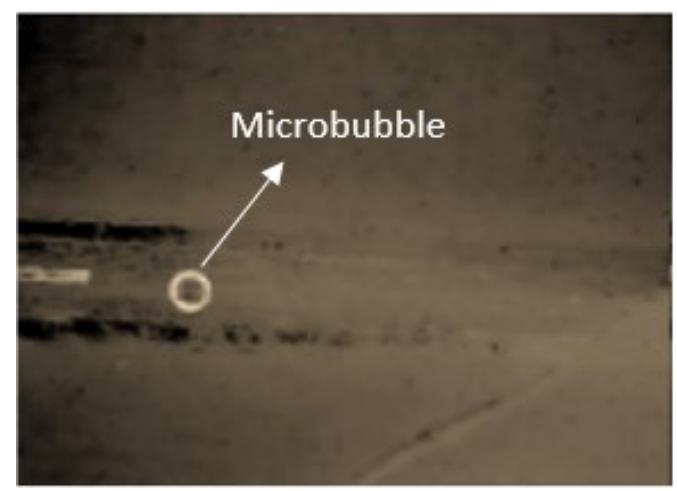

Figure 5 Microbubble generated from the microfluidic devices.

Every generation process is monitored through a high-speed camera. The images are then processed using a computational tool (MatLab®) where statistical data related to the generation of microbubbles, such as poly dispersion, mean diameter, distribution curves, etc.

The microfluidic systems manufactured according to the aforementioned technique partially met the expectations regarding the uniformity of the population of microbubbles produced, and the obtainment of diameters close to the ideal, which is around $10 \mu \mathrm{m}$ (approximate size of a red cells). Microbubbles with diameters greater than the aforementioned values can cause gas embolism to the patient since the microbubbles will be administered intravenously. A difficulty encountered in the operationalization of the production process is associated with the encapsulation of the micropipette in the microfluidic device. The micropipette encapsulation results from the impossibility of the printer Objet Eden 250 to manufacture channels of the order of $10 \mu \mathrm{m}$ due to the print resolution. Using the micropipette was a way to get around the problem, given that the microbubble diameter is closely linked to the opening of the gas phase channel (micropipette tip) P Garstecki, I Gitlin, W Diluzio, GM Whitesides, E Kumacheva, 2004. 
According to Garstecki, the microbubble radius (r) is determined by an experimental relationship that relates the opening of the gas phase (W), in addition to the gas phase $(\mathrm{QG})$ and liquid phase $(\mathrm{QL})$ flow rates, as shown in Equation.

$$
\frac{r}{w}=1+\alpha \frac{Q_{G}}{Q_{L}}
$$

In the particular case, the micropipette is the structure responsible for nourishing the compatible opening for the generation of microbubbles within the size specifications mentioned above, that is, with diameters equal to $10 \mu \mathrm{m}$. The constant $\alpha$ for the particular case is approximately equal to 1 Garstecki, P. 2010.

Due to the dimensioning of the gas phase channel diameter, the encapsulation procedure becomes very critical, causing large disposal of micropipettes in the process. To overcome this difficulty, a new project for a microfluidic device is being proposed, aiming to eliminate the aforementioned critical procedure, which will certainly optimize the microbubble production process.

\section{DEVELOPMENT}

\section{Proposed microfluidic device design}

Below are the images of the devices designed with the aim of overcoming the aforementioned difficulties.

Figure 6 presents a three-dimensional image of the assembled device.

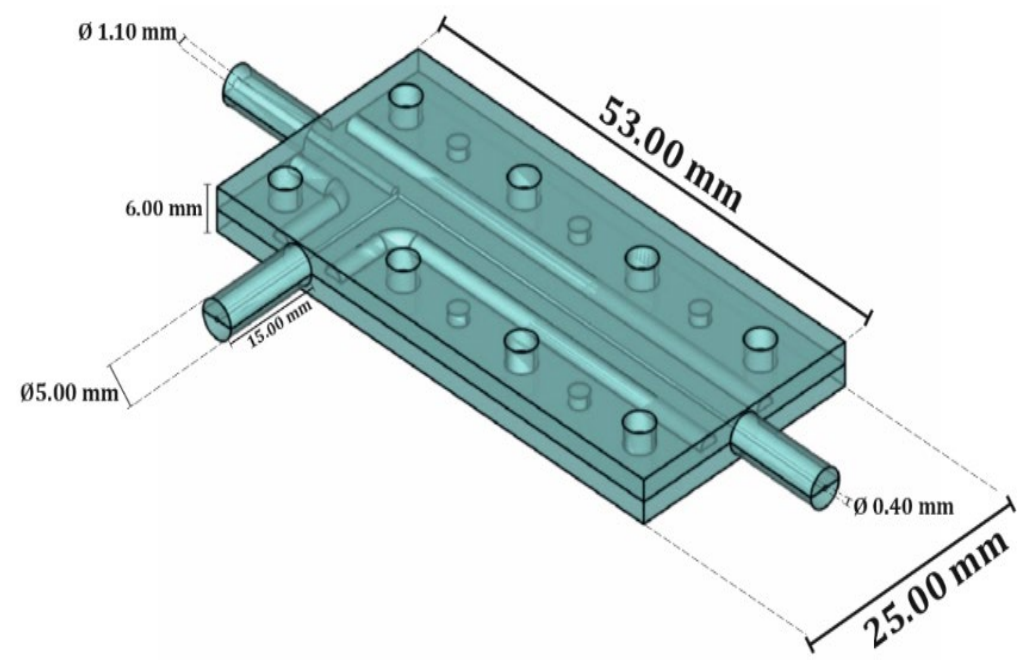

Figure 6 Three-dimensional image of the assembled microfluidic device.

Figure 7 shows a top view of the device with its dimensional characteristics. 


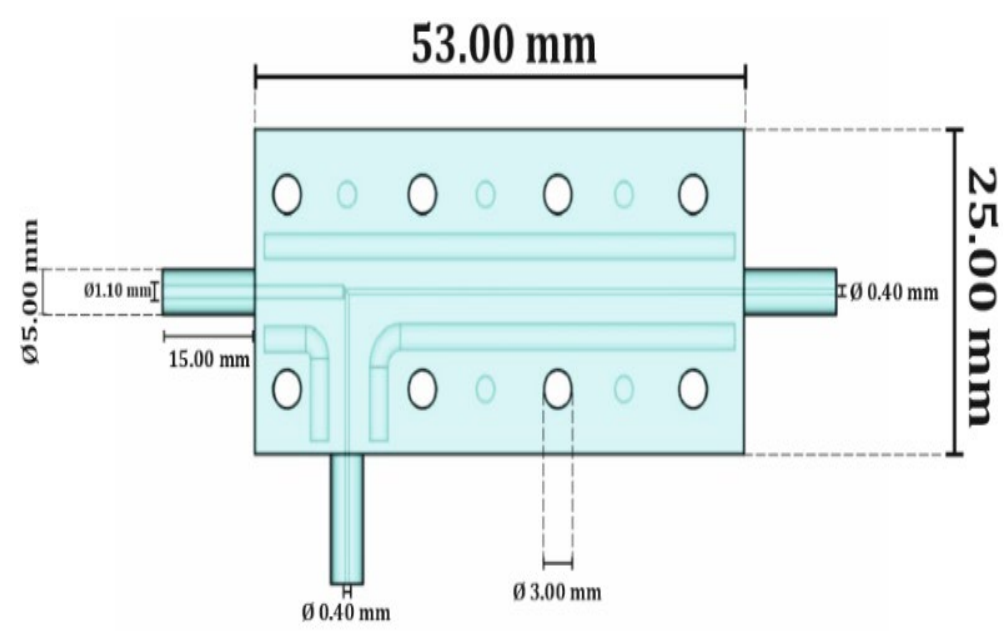

Figure 7 Top view of the device with its dimensional characteristics

To circumvent the problems of encapsulating the micropipette, a sandwichtype device was designed, that is, two custom-made parts that overlap, causing the formation of closed conduction ducts. The encapsulation of the micropipette takes place before the fitting of the parts that make up the device. Figure 7 shows the device configuration before fitting parts $\mathrm{A}$ and $\mathrm{B}$.

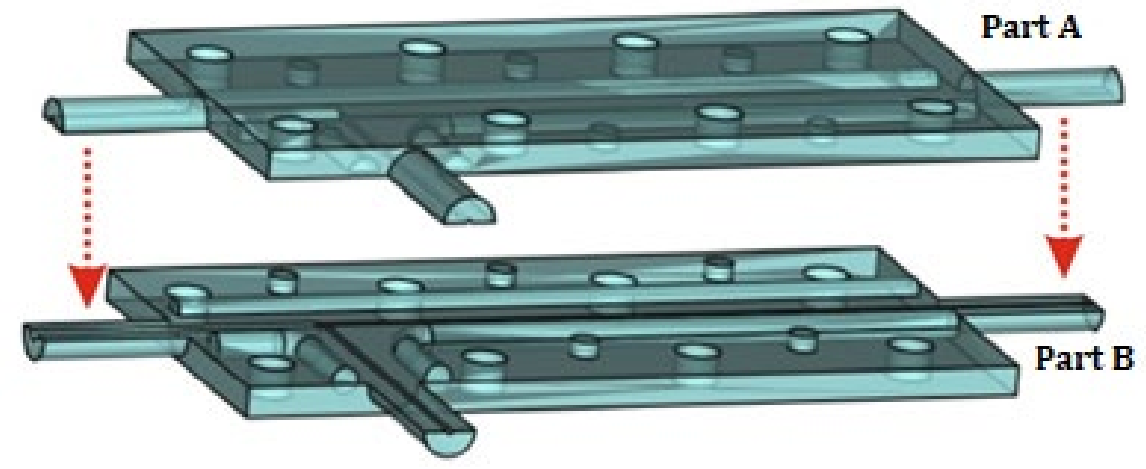

Figure 8 Device configuration before fitting overlapping parts.

The projected device will provide a significant improvement in the operation of microbubble generation, in addition to reducing costs related to the disposal of micropipettes in their encapsulation process.

Figure 9 shows the positioning of the micro capillary (micropipette) and the process of generating the microbubbles in the bifurcation of the liquid and gas phases. It also presents the physical characteristics of the microbubble and its composition. 


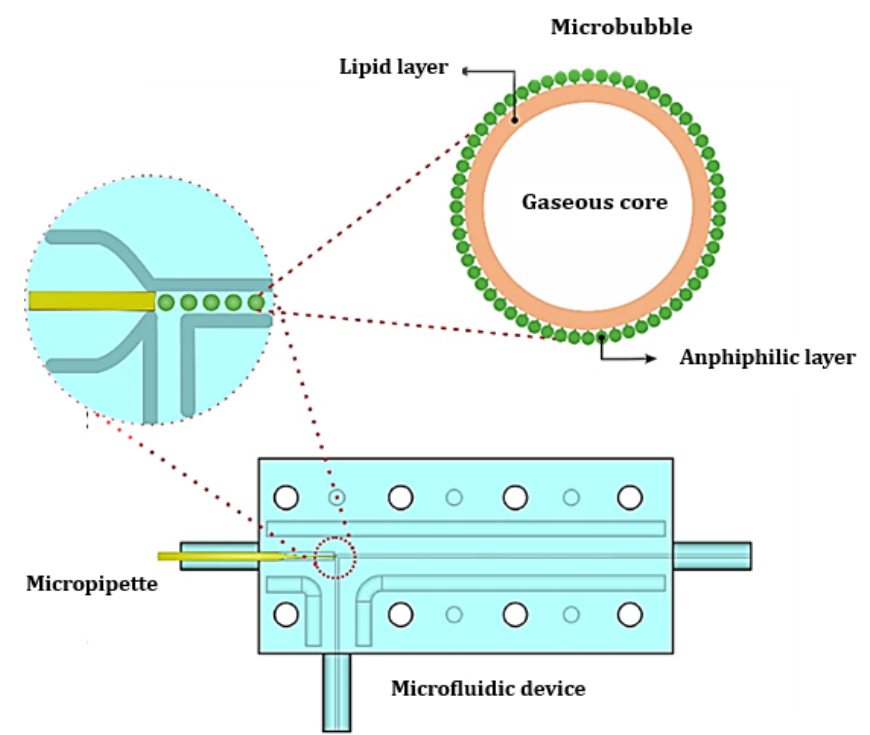

Figure 9 Positioning of the micro capillary (micropipette) and the process of generating the microbubbles in the bifurcation of the liquid and gas phases. It also presents the physical characteristics of the microbubble and its composition.

\section{Future perspectives}

Due to the physical characteristics of the microbubble, notably in relation to its lipid coating layer, the search for drug transport systems is an important strategy. The search for specialized drug transport systems, using macromolecules as carriers and site-specific delivery systems, are biopharmaceutical and therapeutic trends for the treatment, diagnosis, monitoring and control of biological systems. The application of nanotechnology in Medicine emerged in the 1960s, with the initial development of microencapsulation, a technique for transforming liquids (polymers and other substances) into powders with micrometric particle size Allen, M. T., Cullis, R. P. 2012.

Microencapsulation is widely used in the food, textile, pharmaceutical and cosmetic industries as it allows the protection of labile and volatile substances, the control of drug release, contributing to the improvement in bioavailability, reduction of therapeutic dose and toxicity. Microencapsulation served as a model for more sophisticated techniques, currently at the nanometer scale, allowing the development of nanoparticles. The main systems developed for the transport of drugs can be divided into microsystems, contemplated by multiple emulsions and microemulsions, and nanosystems that use liposomes and polymeric nanoparticles Bizerra, A., Silva, V. 2016.

In 1965, Bangham et al. published the first description of phospholipid systems and laid the foundation for the model of membrane systems. Subsequently, a variety of closed phospholipid bilayer structures consisting of single bilayers were described, and early pioneers such as Gregory Gregoriadis established the concept of liposomes, aqueous vesicles surrounded by bilayers. lipid, which can serve as a vehicle for drugs to be encapsulated in the aqueous cavity of the vesicle or in the lipid bilayer Fillippin, B. F., Souza, C. L. 2006. In the 1990s, more sophisticated nanosystems coated with hydrophilic polymers appeared, called stealth systems, which allow a longer circulation time in the body Gref, R., Minamitake, Y., Peracchia, 
M. T., Trubetskoy, V., Torchilin, V., Langer, R. 1994. In addition to stealth systems, systems containing signaling molecules on the surface called site-specific were developed with the purpose of specific targeting of drugs to target cells Allen, M. T., Cullis, R. P. 2012, Gref, R., Minamitake, Y., Peracchia, M. T., Trubetskoy, V., Torchilin, V., Langer, R. 1994, Barrat, G. M. 2000.

The main nanosystems used for drug transport use polymeric nanoparticles, liposomes, cyclodextrins and dendrimers. Polymeric nanoparticles are drug carrier systems that have a diameter of less than 1 micron Allen, M. T., Cullis, R. P. 2012, Bizerra, A., Silva, V. 2016. Nanoparticles are classified into two different types of structures: nanocapsules and nanospheres. Nanocapsules are reservoir-type systems, and this configuration consists of a nucleus containing the drug, which can be in solid or liquid state (Figure 10 - $\mathrm{a}$ and b). In this case, the active principle is coated with a polymeric membrane or permeable wall. Nanospheres are characterized by matrix or monolithic systems, in which the drug is homogeneously incorporated or adsorbed into the structure of a polymer or a union of polymers, with variable chemical composition and properties (Figure 10 - $\mathrm{c}$ and d).

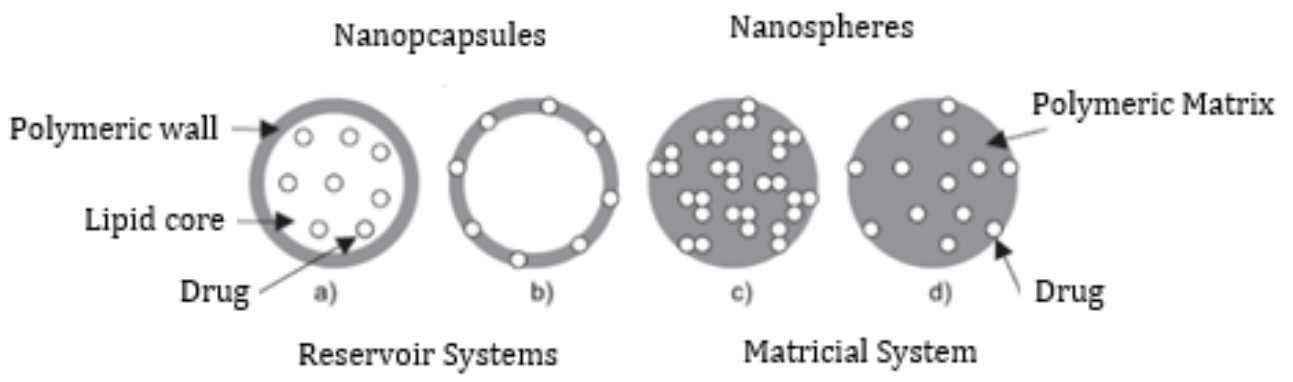

Figure 10 Representation of nanospheres and nanocapsule

Source: Schaffazick, R. S., Guterres, S. S. 2003.

Liposomes are aqueous vesicles formed by concentric bilayers of phospholipids, an excellent form of controlled drug delivery system, due to its structural flexibility (size, composition and fluidity of the lipid bilayer). In addition, an important parameter to be considered is the ability to incorporate a variety of hydrophilic and hydrophobic compounds, being the most clinically established nanometric systems for the delivery of cytotoxic drugs Pontes, A. C., Caetano, M. N., Magalhaes, N. S. 1999.

Liposomes and microbubbles can have varying sizes $(20 \mathrm{~nm}$ to 10 micrometers) with lipid bilayer thickness around $6 \mathrm{~nm}$, as controlled drug delivery systems not only enable vectorization and drug protection, but also allow targeting to specific sites of cells or organs (site-specific) Allen, M. T., Cullis, R. P. 2012, Bizerra, A., Silva, V. 2016. They can encapsulate hydrophilic and/or lipophilic substances, the former being in the aqueous compartment and the lipophilic ones inserted or adsorbed on the microstructure membrane. Because they are biodegradable, biocompatible and non-immunogenic, they are highly versatile for research, therapeutic and analytical applications Pontes, A. C., Caetano, M. N., Magalhaes, N. S. 1999. The intravenous route is the main route of administration of liposomes and microbubbles Sharma, P., Mukherjee, A., Karunanithi, S., Bal, C., Kumar, R. 2014. 
Like liposomes, microbubbles can contain a single lipid bilayer or multiple bilayers around the internal aqueous or gaseous compartment, being therefore classified as unilamellar and multilamellar, respectively Sharma, P., Mukherjee, A., Karunanithi, S., Bal, C., Kumar, R. 2014. This type of structure allows the encapsulation of compounds of hydrophilic, hydrophobic and amphiphilic nature, and the controlled release of the encapsulated content by diffusion and/or erosion of the vesicle or by the action of an ultrasonic field Pontes, A. C., Caetano, M. N., Magalhaes, N. S. 1999, Sharma, P., Mukherjee, A., Karunanithi, S., Bal, C., Kumar, R. 2014. The in vivo pharmacokinetics and distribution can be controlled by the size and lipid composition of these structures Bizerra, A., Silva, V. 2016.

Numerous studies have shown that the distribution of a drug in the body can be modified by the use of microsystems and nanosystems such as liposomes and microbubbles. These carriers can protect the active ingredient from degradation and/or inactivation; improve bioavailability by increasing cell penetration and provide drug release at the desired site of action, eliminating or minimizing the side effects of conventional therapy Allen, M. T., Cullis, R. P. 2012, Bizerra, A., Silva, V. 2016, Gref, R., Minamitake, Y., Peracchia, M. T., Trubetskoy, V., Torchilin, V., Langer, R. 1994. Table 1 presents some potential drugs for transport by microfluidic device for the generation of monodisperse microbubbles.

Table 1 Potential drugs for transport by microfluidic device for the generation of monodisperse microbubbles

\begin{tabular}{|c|c|c|}
\hline Drugs & Character & Formulation \\
\hline $\begin{array}{c}\text { Cisplatin (cis- } \\
\text { diaminodichloroplatinum (II)) }\end{array}$ & $\begin{array}{cc}\text { - } & \text { antineoplastic agent } \\
\text { - } & \text { heavy metal complex } \\
\text { - } \quad \text { water soluble } \\
\text { high plasma protein } \\
\text { binding rate }\end{array}$ & \\
\hline Cyclophosphamide (CPA) & $\begin{array}{cc}\text { - } & \text { immunosuppressive } \\
\text { agent } \\
\text { - } & \text { anticancer agent } \\
\text { - } & \text { highly mutagenic }\end{array}$ & \\
\hline
\end{tabular}

Cisplatin [cis-diaminodichloroplatinum (ii)] belongs to the group of platinum coordination complexes that were identified as cytotoxic agents by Rosenberg et al. in the 60s, when they were studying the growth of an Escherichia Coli bacterium in the presence of an electric field. Rosenberg observed that, despite the bacteria growing, they no longer reproduced, with cis-diaminodichloroplatinum (II) or cisplatin being responsible for interrupting this process Neves, A. P., Vargas, M. D. 2011, Ferguson, H. M., Fréchet, J., Szoka, F. C. 2013.

Cisplatin (CDDP) had been known since 1845 as Peyrone's chloride, after the Italian chemist Michele Peyrone (1813-1883) who first synthesized it. Its structure was correctly proposed in 1893 by Alfred Werner Shen, S., Kuznetsov, I., Abakumova, T., Chelushkin, P., Melnikov, P., Korchagina, A., Bychkov, D., Seregina, F., Bolshov, M., Kabanov, A., Chekhonin, V., Nukolova, N. 2016. Cisplatin entered phase I clinical trials in 1971 and in 1978 received approval from the US Food and Drugs 
Administration (FDA) for use in the treatment of genitourinary cancers. Shortly thereafter, its use became popular in the United States, being marketed as Platinol (Bristol-Meyers Squibb) and released for medical use Shen, S., Kuznetsov, I., Abakumova, T., Chelushkin, P., Melnikov, P., Korchagina, A., Bychkov, D., Seregina, F., Bolshov, M., Kabanov, A., Chekhonin, V., Nukolova, N. 2016, Huang, X., Li, Z., Yu, Z., Deng, X., Yi, X. 2019.

The chemotherapeutic properties of cisplatin and its analogues are related to the flat-square geometry (d8) and "cis"-type isomerism of these complexes. The Pt$\mathrm{N}$ bond is kinetically inert and thermodynamically stable, while the chlorine ligands are better leaving groups. Furthermore, in the biological environment, there is an equilibrium shift related to the difference in the concentration of chloride ions inside and outside the cell, causing the chlorine ligands to be replaced by water in a hydrolysis process Huang, X., Li, Z., Yu, Z., Deng, X., Yi, X. 2019, Ferguson, H. M., Fréchet, J., Szoka, F. C. 2013.

Cisplatin (CDDP) is one of the most potent and widely used antitumor agents. It exhibits activity against a wide variety of solid tumors and is approved for the clinical treatment of a variety of tumors, including metastatic testicular cancer, breast, advanced bladder, and non-small cell lung cancer. It is the most widely used chemotherapy drug, the gold standard for epithelial malignancies that account for over $80 \%$ of human cancers Neves, A. P., Vargas, M. D. 2011. However, severe side effects (nephrotoxicity, neurotoxicity and ototoxicity, nausea and vomiting) associated with the off-target distribution of CDDP significantly limit its clinical use Shen, S., Kuznetsov, I., Abakumova, T., Chelushkin, P., Melnikov, P., Korchagina, A., Bychkov, D., Seregina, F., Bolshov, M., Kabanov, A., Chekhonin, V., Nukolova, N. 2016.

Biochemical approaches designed to modulate CDDP toxicity have not been successful. Efforts to create new platinums with decreased toxicity were only partially successful and only 3,000 developed compounds entered clinical trials, with five approved for clinical use worldwide (carboplatin and oxaliplatin) or regionally nedaplatin, heptaplatin and lobaplatin. Most of the above analogues have shown improved toxicity profiles compared to CDDP, but this advantage is gained at the expense of reduced efficacy Neves, A. P., Vargas, M. D. 2011, Shen, S., Kuznetsov, I., Abakumova, T., Chelushkin, P., Melnikov, P., Korchagina, A., Bychkov, D., Seregina, F., Bolshov, M., Kabanov, A., Chekhonin, V., Nukolova, N. 2016.

The mechanism of action of cisplatin indicates that, upon entering the cell, this drug undergoes successive hydrolysis reactions to form the activated species [Pt $(\mathrm{NH} 3) 2 \mathrm{Cl}(\mathrm{OH} 2)]+$ and [Pt $(\mathrm{NH} 3) 2(\mathrm{OH} 2) 2] 2+$, which react more quickly to cellular targets. Outside the cell, the high concentration of chloride prevents hydrolysis and maintains cisplatin in its neutral form [Pt (NH3)2Cl2] while the low concentration of chloride in the intracellular medium favors the formation of hydrolyzed species Neves, A. P., Vargas, M. D. 2011, Shen, S., Kuznetsov, I., Abakumova, T., Chelushkin, P., Melnikov, P., Korchagina, A., Bychkov, D., Seregina, F., Bolshov, M., Kabanov, A., Chekhonin, V., Nukolova, N. 2016, Huang, X., Li, Z., Yu, Z., Deng, X., Yi, X. 2019.

The biochemical mechanisms involved in the entry of cisplatin into the cell are still under investigation, but passive diffusion was, for a long time, considered the main way in which this compound crosses the cell membrane. More recent studies point to the importance of active diffusion, through the participation of copper transporters and organic cationic transporters Shen, S., Kuznetsov, I., Abakumova, T., Chelushkin, P., Melnikov, P., Korchagina, A., Bychkov, D., Seregina, F., Bolshov, M., Kabanov, A., Chekhonin, V., Nukolova, N. 2016. 
The fragment "Pt (NH3)2" can bind to DNA in different ways. The studies showed that the N7 atoms of the purine bases (G or A), located in the major groove, are the preferred sites of coordination with platinum, because they are more accessible and more nucleophilic, compared to other nitrogen atoms. The main cisplatin-DNA interaction formed results from the 1,2-intraphyte crosslink, in which platinum (II) is found linked to two adjacent bases (G-G, $60 \%$ or A-G $20 \%$ ). Other less common interactions are those in which platinum (II) makes the following bonds Huang, X., Li, Z., Yu, Z., Deng, X., Yi, X. 2019, Ferguson, H. M., Fréchet, J., Szoka, F. C. 2013:

1) To two bases on different strands (interstrand interaction)

2) To a strand of DNA and a protein

3) To two non-adjacent bases resulting in 1,3-intraphyte crosslinking

The formation of adducts with cisplatin causes significant distortions in the DNA double helix, causing unfolding and twisting of its structure, which in turn are responsible for inducing apoptosis (programmed cell death) and necrosis Sharma, P., Mukherjee, A., Karunanithi, S., Bal, C., Kumar, R. 2014, Huang, X., Li, Z., Yu, Z., Deng, X., Yi, X. 2019. Despite having therapeutic activity, the use of cisplatin presents some obstacles. Its low solubility, for example, makes it to be administered intravenously. There are also serious side effects, such as hearing loss, nephrotoxicity, neurotoxicity, among others, and, as it is a non-selective molecule, it also acts on healthy cells. In addition to cisplatin, two other platinum (II)-based compounds have been approved by the FDA for cancer therapy, carboplatin in 1989 and oxaliplatin in 2002 Ferguson, H. M., Fréchet, J., Szoka, F. C. 2013. Due to side effects, there is great interest in developing a new generation of platinum-based anticancer drugs, including Pt (IV) prodrugs, in order to overcome or minimize the toxic effects of cisplatin and expand the therapeutic spectrum for different types of cancers Huang, X., Li, Z., Yu, Z., Deng, X., Yi, X. 2019, Ferguson, H. M., Fréchet, J., Szoka, F. C. 2013.

CDDP transport using nanoparticles aggregated to the lipid layer of the microbubble seems to be a more promising strategy, as it can potentially improve the toxicity profile and retain high antitumor efficacy. To date, a wide variety of different nanocontainers have been offered as CDDP carriers Huang, X., Li, Z., Yu, Z., Deng, X., Yi, X. 2019. Being of nanoscale size, they all exploit the effect of increased permeability and retention (EPR) to passively accumulate in tumors. Among several nanocarriers, liposomes (ie, 50-500 nm spherical lipid bilayers with an aqueous interior) are the most promising Shen, S., Kuznetsov, I., Abakumova, T., Chelushkin, P., Melnikov, P., Korchagina, A., Bychkov, D., Seregina, F., Bolshov, M., Kabanov, A., Chekhonin, V., Nukolova, N. 2016, Huang, X., Li, Z., Yu, Z., Deng, X., Yi, X. 2019. Several liposome-based drugs have been approved for clinical use. They are intrinsically biocompatible, as naturally occurring lipids are used in liposomal compositions and their outer surface can be easily modified, thus conferring several properties Shen, S., Kuznetsov, I., Abakumova, T., Chelushkin, P., Melnikov, P., Korchagina, A., Bychkov, D., Seregina, F., Bolshov, M., Kabanov, A., Chekhonin, V., Nukolova, N. 2016.

The liposomal formulation of cisplatin, known as lipoplatin (Lipoplatin), is a cisplatin nanoparticle that can be encapsulated in liposomes and microbubbles and is formed from dipalmitoyl phosphatidyl glycerol (DPPG), soy phosphatidyl choline (SPC-3) compounds. cholesterol and methoxy-polyethylene glycol-distearoyl phosphatidylethanolamine (mPEG2000-DSPE) (Figure 11). 


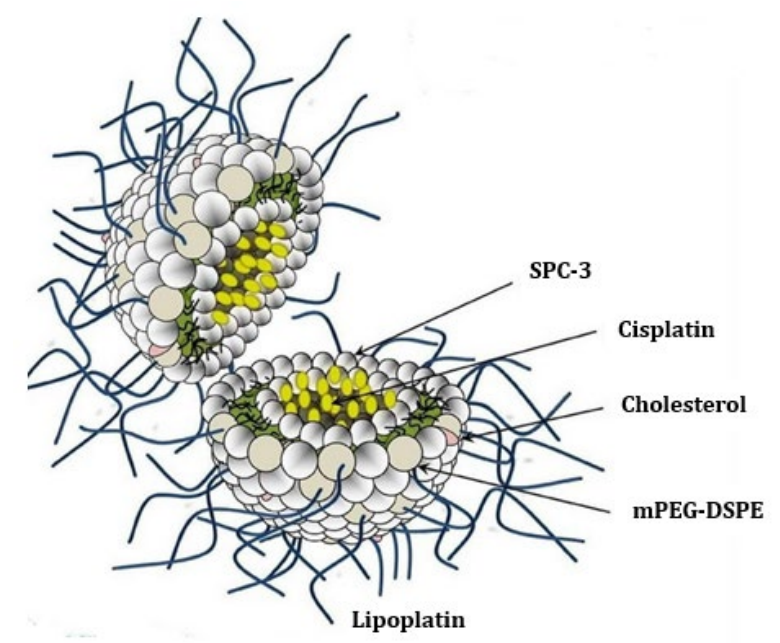

Figure 11 Representation of cisplatin encapsulated by liposomes -Lipoplatin

It is currently in phase III clinical trials, being developed with the aim of reducing the systemic cytotoxicity of cisplatin and at the same time that it improves the drug's targeting to the primary tumor and metastases, it increases the circulation time in fluids and tissues. bodily. In it, cisplatin is surrounded by a 110 $\mathrm{nm}$ lipid layer, which is not recognized by macrophages or immune system cells. Once encapsulated in liposomes, the concentration of cisplatin in tumor tissues can be increased up to 50 times that of normal tissues Shen, S., Kuznetsov, I., Abakumova, T., Chelushkin, P., Melnikov, P., Korchagina, A., Bychkov, D., Seregina, F., Bolshov, M., Kabanov, A., Chekhonin, V., Nukolova, N. 2016,Ferguson, H. M., Fréchet, J., Szoka, F. C. 2013.

Methotrexate (MTX), called 4-Amino-N10-Methylpteroyl Glutamic Acid, is characterized as an orange powder, with a molecular weight of $454.44 \mathrm{~g} / \mathrm{mol}$ and chemically constituted by a heterocyclic portion (2,4-diamino substituted pterin ring) linked to the $\rho$-aminobenzoyl portion which is linked to the glutamic acid unit. It has three pKa values; 3.4 and 4.7 (referring to carboxyl groups) and 5.7 of the pterin ring nitrogen group, so its solubility in aqueous media is $\mathrm{pH}$-dependent, being little soluble in acidic pH and very soluble in alkaline pH. MTX is classified as class III in the Biopharmaceutical Classification System, that is, it has high solubility and low permeability, a characteristic that limits its oral administration in the treatment of pathologies such as colon cancer Puig, L. 2014. As it is a folic acid analogue, MTX has the ability to bind strongly to the reduced folate transporter to be transported to the intracellular environment, where it undergoes polyglutamation by the foliopolyglutamyl synthase enzyme, being converted into polyglutamate derivatives with the same activity. This process allows the retention and increase of the intracellular half-life of MTX, which in its free form undergoes efflux Abolmaali, S. S., Tamaddon, A. M., Dinarvand, R. 2013.

MTX belongs to the class of classic chemotherapeutics and has a high affinity for the enzymes dihydrofolate reductase (DFHR) involved in purine and pyrimidine synthesis pathways. These nitrogenous bases are precursors of DNA and RNA synthesis, therefore, as a result of the inhibition of the pathways, there is an interruption of DNA replication and cell death Abolmaali, S. S., Tamaddon, A. M., Dinarvand, R. 2013, Sorbello, G. S., Bertino, J. R. 2001. MTX can be administered orally, subcutaneously, intramuscularly or intravenously, the oral bioavailability in 
low doses is high (70\%), although it varies from patient to patient. At doses above $15 \mathrm{mg}$, bioavailability drops to $30 \%$, as MTX uptake by the gastrointestinal tract is mediated by a saturable transporter, the reduced folate transporter. The preferred route of administration in such cases is usually parenteral, which is also associated with better gastrointestinal tolerability Puig, L. 2014, Sorbello, G. S., Bertino, J. R. 2001.

As for the mechanism of action, MTX inhibits the proliferation of neoplastic cells, blocking the synthesis of purines and pyrimidines by irreversibly inhibiting dihydrofolate reductase, which is responsible for the production of tetrahydrofolate. Although high doses of folic or folinic acid can reverse this effect, supplementation of folic and folinic acid in inflammatory diseases is not used for this purpose, but to prevent MTX toxicity without significantly reducing treatment effectiveness Allen, M. T., Cullis, R. P. 2012. Despite being one of the drugs of choice for the treatment of colorectal cancer and inflammatory bowel diseases (IBD), its high cytotoxicity and low selectivity are responsible for a series of undesirable effects on healthy organs and tissues, presenting several adverse effects that make it difficult to patient compliance and dose adjustment Sorbello, G. S., Bertino, J. R. 2001. The gastrointestinal mucosa and bone marrow are the tissues most vulnerable to the effects of MTX, mainly due to the intense rate of cell proliferation Gaies, E., Jebabli, N., Trabelsi, S., Salouage, I., Charfi, R., Lakhal, M., Klouz, A. 2012. The drug can induce a number of disorders, such as abdominal pain, vomiting, nausea and diarrhea, effects that are accentuated on oral administration in addition to the hepatotoxicity and nephrotoxicity that can also be caused during therapy Gaies, E., Jebabli, N., Trabelsi, S., Salouage, I., Charfi, R., Lakhal, M., Klouz, A. 2012, Levêque, D., Santucci, R., Gourieux, B., Herbrecht, R. 2011. It is expected that this drug carried by both liposomes and microbubbles can minimize side effects due to its cytotoxicity, since its action has a more localized action.

\section{CONCLUSION}

As stated above, the microbubble generation technique using microfluidic devices manufactured according to 3D printing achieved very low levels of polydispersion and diameters very close to $10 \mu \mathrm{m}$, which corresponds to the ideal size for intravenous application without risk of gas embolism in the patient. With the new device project, it is expected to overcome the aforementioned difficulties, enabling the reduction of operating costs in the process of encapsulating microcapillaries (micropipettes) in the microfluidic device.

In view of the obstacles imposed on the conventional treatment of tumor diseases, the need to explore new pharmaceutical technologies is highlighted, in order to make the therapy more targeted and effective. Thus, the rational development of nano and microstructures as a vehicle for the transport of drugs can improve the effects of oral administration and increase biological interaction, minimizing side effects, improving the patient's quality of life.

\section{ACKNOWLEDGMENT}

State Universityof Bahia (UNEB)(Salvador-Brazil), and Renato Archer Information Technology Center (CTI) (Campinas-São Paulo-Brazil). 


\section{REFERENCES}

Abolmaali, S. S., Tamaddon, A. M., Dinarvand, R. 2013. "A review of therapeutic challenges and achievements of methotrexate delivery systems for treatment of cancer and rheumatoid arthritis". Cancer Chemotherapy Pharmacololy. 71:1115-1130. Retrived from https://doi.org/10.1007/s00280-012-2062-0

Allen, M. T., Cullis, R. P. 2012. "Liposomal drug delivery systems: From concept to clinical applications". Advanced Drug Delivery Reviews, 65:36-48. Retrived from https://doi.org/10.1016/j.addr.2012.09.037

Araujo Filho, W. D. et al. "Evaluation of stability and size distribution of sunflower oil coated micro bubbles for localized drug delivery. Biomedical Engineering OnLine,11:71. Retrived from https://doi.org/10.1186/1475-925X-11-71

Araujo Filho, W. D.; Araujo, L. M.P. Monodisperse Microbubbles as Drug Carrier Units Having the Olive Oil as the Coating Layer from Devices Manufactured by 3D Printing. International Journal of Biosensors \& Bioelectronics, v. 3, p.00059-00064, 2017. Retrived from https://doi.org/10.15406/ijbsbe.2017.03.00059

Araujo Filho, W. D.; Araujo, L. M.P.; Menezes, D. O.; Mauricio, C. R. M. 2019 3D Printing Techniques in the Manufacture of Microfluidic Devices for Generation of Microbubbles. SCIOL Biomedicine, v. 3, p. 143,.

Araujo Filho, W. D.; Araujo, L. M.P.; Menezes, D. O.; Mauricio, C. R. M. Annexation of Biologically active compounds extracted from plants in the lipid layers of microbubbles for the localized treatment of diseases. DISEASES.INTERNATIONAL JOURNAL OF CURRENT RESEARCH, v. 10, p. 72208-72211, 2018.

Barrat, G. M. 2000. "Therapeutic applications of colloidal drug carriers". Pharma. Sci. Technol. 5:163-171. Retrived from https://doi.org/10.1016/S14615347(00)00255-8

Bizerra, A., Silva, V. 2016. "Sistema de Liberação controlada. Revista de Saúde e Meio ambiente". Mato Grosso. 3(2):1-12.

Borden, M. A., M. L. Longo. 2002. "Dissolution behaviour of lipid monolayer coated, air-filled micro bubbles: Effect of lipid hydophobic chain length". Langmuir. 18(24):9225-9233. Retrived from https://doi.org/10.1021/la026082h

E stride, M Edirisinghe 2008. Novel microbubble preparation technologies. soft Matter; 4:2350. Retrived from https://doi.org/10.1039/b809517p

EC Unger, T Porter, W Culp, R label, T Matsunaga, R Zutshi 2004. Therapeutic applications of lipid-coated microbubbles. adv Drug Deliv Rev; 56:1291-314. Retrived from https://doi.org/10.1016/j.addr.2003.12.006

Ferguson, H. M., Fréchet, J., Szoka, F. C. 2013. "Clinical developments of chemotherapeutic nanomedicines: polymers and liposomes for delivery of camptothecins and platinum (II) drugs". WIREs Nanomedicine and Nanobiotechnology. 5(2):130-138. Retrived from https://doi.org/10.1002/wnan.1209

Fillippin, B. F., Souza, C. L. 2006. "Eficiência terapêutica das formulações lipídicas de anfotericina B". Revista Brasileira de Ciências Farmacêuticas. 42:167-194. Retrived from https://doi.org/10.1590/S1516-93322006000200003 
Fiorini, D. T. Chiu 2005. Disposable microfluidic devices: Fabrication, function, and application. Bio techniques; 38:429-46. Retrived from https://doi.org/10.2144/05383RV02

Gaies, E., Jebabli, N., Trabelsi, S., Salouage, I., Charfi, R., Lakhal, M., Klouz, A. 2012. "Methotrexate Side Effects: Review Article". Drug Metabolism \& Toxicology. 3(4):1-5. Retrived from https://doi.org/10.4172/2157-7609.1000125

Garstecki, P. 2010. "Formation of Droplets and Bubbles in Microfluidic Systems". Microfluidics Based Microsystems: Fundamentals and Applications". 163181. Retrived from https://doi.org/10.1007/978-90-481-9029-4_9

Gref, R., Minamitake, Y., Peracchia, M. T., Trubetskoy, V., Torchilin, V., Langer, R. 1994. "Biodegradable long-circulating polymeric nanospheres". Science. 263:1600-1603. Retrived from https://doi.org/10.1126/science.8128245

Huang, X., Li, Z., Yu, Z., Deng, X., Yi, X. 2019. "Recent Advances in the Synthesis, Properties, and Biological Applications of Platinum Nanoclusters". Journal of Nanomaterials. 2019:6248725. Retrived from https://doi.org/10.1155/2019/6248725

Lajoline, G. et al. 2016. In vitro methods to study bubble-cell interactions: Fundamentals and therapeutic applications. Bio microfluidics, v. 10, n. 1, p. 011501. Retrived from https://doi.org/10.1063/1.4940429

Levêque, D., Santucci, R., Gourieux, B., Herbrecht, R. 2011. "Pharmacokinetic drugdrug interactions with methotrexate in oncology". Expert Review of Clinical Pharmacology. 4(6):743-750. Retrived from https://doi.org/10.1586/ecp.11.57

Lindner, J. R., S. Kaul. 2001. "Delivery of drugs with ultrasound Echocardiography." 18(4): 329-337. 2001. Retrived from https://doi.org/10.1046/j.15408175.2001.00329.x

Neves, A. P., Vargas, M. D. 2011. "Complexo de Platina (II) na Terapia do Câncer". Revista Virtual de Quimica. 3:196-209. Retrived from https://doi.org/10.5935/1984-6835.20110023

P Garstecki, I Gitlin, W Diluzio, GM Whitesides, E Kumacheva, 2004 Ha stone . Formation of monodisperse bubbles in a microfluidic flow-focusing device. appl Phys lett; 85:2649-51. Retrived from https://doi.org/10.1063/1.1796526

Pancholi, K., E. Stride, et al. 2008. "Generation of microbubbles for diagnostic and therapeutic applications using a novel device. "J Drug Target., 16(6): 494501. https://doi.org/10.1080/10611860802184884

Pontes, A. C., Caetano, M. N., Magalhaes, N. S. 1999. "Physicochemical characterization and antimicrobial activity of benzathine penicillin G liposomes". S. T. P. Pharma Sci. 9:419-427.

Puig, L. 2014. "Methotrexate: New Therapeutic Approaches". Actas Dermosifiliogr. 6:583-589. Retrived from https://doi.org/10.1016/j.ad.2012.11.017

Schaffazick, R. S., Guterres, S. S. 2003. "Caracterização e estabilidade físico-química de sistemas poliméricos nanoparticulados para administração de fármacos". Qumica Nova. 26(5):726-737. Retrived from https://doi.org/10.1590/S0100-40422003000500017 
Sharma, P., Mukherjee, A., Karunanithi, S., Bal, C., Kumar, R. 2014. "Potencial role of ISF-FDG, PET/CT in patients with fungal infection". Am. J. Roentgenol. 203:180-189. Retrived from https://doi.org/10.2214/AJR.13.11712

Shen, S., Kuznetsov, I., Abakumova, T., Chelushkin, P., Melnikov, P., Korchagina, A., Bychkov, D., Seregina, F., Bolshov, M., Kabanov, A., Chekhonin, V., Nukolova, N. 2016. "VEGF- and VEGFR2-Targeted Liposomes for Cisplatin Delivery to Glioma Cells". Mol. Pharmaceutics. 13:3712-3723. Retrived from https://doi.org/10.1021/acs.molpharmaceut.6b00519

Sorbello, G. S., Bertino, J. R. 2001. "Current understanding of methotrexate pharmacology and efficacy in acute leukemias. Use of newer antifolates in clinical trials". Haematologica. 86(2):121-127. Retrived from https://doi.org/10.3324/\%25x

Stride, E. 2009. "Physical principles of micro bubbles for ultrasound imaging and therapy. "cerebrovascular Dis 27 Suppl, 2: 1-13. Retrived from https://doi.org/10.1159/000203122

Stride, E. 2009. "Physical principles of micro bubbles for ultrasound imaging and therapy. "cerebrovascular Dis 27 Supply, 2: 1-13. Retrived from https://doi.org/10.1159/000203122

Stride, E., M. Edrisinghe. 2009. "Novel preparation techniques for controlling micro bubble uniformity: a comparison. "Med Biol Eng Comput., 47(8): 883-892. Retrived from https://doi.org/10.1007/s11517-009-0490-8

T Fu, Y Ma, D Fun schilling, HZ li 2009. Bubble formation and breakup mechanism in a microfluidic flow-focusing device. Chem Eng sci; 64:2392-400. Retrived from https://doi.org/10.1016/j.ces.2009.02.022

TM Squires, SR Quake 2005. Microfluidics: Fluid physics at the nanoliter scale. Rev Mod Phys; 77:977-1026. Retrived from https://doi.org/10.1103/RevModPhys.77.977

Y Hong, F Wang 2007. Flow rate effect on droplet control in a co-flowing microfluidic device. Micro fluid Nano fluidics; 3:341-6. Retrived from https://doi.org/10.1007/s10404-006-0134-3. 